\title{
Protease-armed bacteria in the skin
}

\author{
Joanna Koziel • Jan Potempa
}

Received: 19 January 2012 / Accepted: 25 January 2012 /Published online: 23 February 2012

(C) The Author(s) 2012. This article is published with open access at Springerlink.com

\begin{abstract}
The skin constitutes a formidable barrier against commensal and pathogenic bacteria, which permanently and transiently colonise the skin, respectively. Commensal and pathogenic species inhabiting skin both express proteases. Whereas proteases secreted by commensals contribute to homeostatic bacterial coexistence on skin, proteases from pathogenic bacteria are used as virulence factors, helping them colonise skin with breached integrity of the epithelial layer. From these initial sites of colonisation, pathogens can disseminate into deeper layers of skin, possibly leading to the spread of infection. Secreted bacterial proteases probably play an important role in this process and in the deterrence of innate defence mechanisms. For example, Staphylococcus aureus proteases are essential for changing the bacterial phenotype from adhesive to invasive by degrading adhesins on the bacterial cell surface. Secreted staphylococcal proteases mediate pathogen penetration by
\end{abstract}

This work was supported by grants from the Polish Ministry of Science and Higher Education N N301 050439 to J.K. and from the National Institutes of Health (grant DE 09761, USA), National Science Center (2011/01/B/NZ6/00268, Kraków, Poland), the European Community (FP7-HEALTH-2010-261460 "Gums\&Joints") and the Foundation for Polish Science (TEAM project DPS/424-329/10) to J.P. The Faculty of Biochemistry, Biophysics and Biotechnology of the Jagiellonian University is a beneficiary of structural funds from the European Union (POIG.02.01.00-12-064/08).

J. Koziel $(\bowtie) \cdot$ J. Potempa

Department of Microbiology, Faculty of Biochemistry, Biophysics and Biotechnology, Jagiellonian University,

ul. Gronostajowa 7,

30-387 Kraków, Poland

e-mail: joanna.koziel@uj.edu.pl

\section{J. Potempa}

Oral Health and Systemic Diseases Research Group,

University of Louisville School of Dentistry,

Louisville, KY, USA degrading collagen and elastin, essential components of connective tissue in the dermis. The activation of the contact system and kinin generation by Streptococcus pyogenes and $S$. aureus proteases contributes to an inflammatory reaction manifested by oedema, redness and pain. Kinin-enhanced vascular leakage might help bacteria escape into the circulation thereby causing possible systemic dissemination of the infection. The inflammatory reaction can also be fueled by the activation of protease-activated receptors on keratinocytes. Concomitantly, bacterial proteases are involved in degrading antimicrobial peptides, disarming the complement system and neutrophils and preventing the infiltration of the infected sites with immune cells by inactivation of chemoattractants. Together, this provides protection for colonising and/or invading pathogens from attack by antibacterial forces of the skin.

Keywords Protease $\cdot$ Skin $\cdot$ Host defense

\section{Skin: structure and function}

Skin is the largest organ in the body and acts as a physical barrier against the external environment. In addition to protecting the body against microorganisms, ultraviolet radiation, toxins, allergens or mechanical insults, skin also regulates the transport of water, electrolytes and some supplements, plus body temperature and metabolism. Skin has four structural layers: the epidermis, basement membrane, dermis and a fat layer, also called the subcutaneous layer (subcutis).

The epidermis, the outer layer of skin, is a dynamic structure composed of keratinocytes, melanocytes, Langerhans cells and Merkel cells. The mature human epidermis consists in four layers (from the innermost layer to the 
surface): the stratum basale (SB), stratum spinosum (SS), stratum granulosum (SG) and stratum corneum (SC). The $\mathrm{SB}$, which lies adjacent to the dermis, comprises mainly dividing undifferentiated keratinocytes, which are attached to the basement membrane by hemidesmosomes. Scattered throughout the basal layer of the epidermis are pigment (melanin)-producing melanocytes. Merkel cells are also found in the basal layer in large numbers at touch-sensitive sites, such as the fingertips and lips. They are closely associated with cutaneous nerves and seem to be involved in light touch sensation. As basal keratinocytes move towards the outer layer of skin, they become connected by desmosomes, initially forming the SS and then they undergo terminal differentiation at the SG and SC layers (Kawakubo et al. 2011). The keratinocyte plasma membrane is replaced with an insoluble protein envelope, inducing aggregation of keratin intermediate filaments via filaggrin. The collapse of their cytoskeleton into flattened squames and the orientation of the keratin proteins add strength to the SC. The resulting non-viable cornifed cells, known as corneocytes and surrounded by lipids, provide the natural physical and waterretaining barrier of the skin (Candi et al. 2005). In most areas of the skin, there are 10-30 layers of dead cells. During terminal differentiation and cornification, granular keratinocytes secrete structural and adhesion proteins, lipids, antimicrobial peptides (AMPs), proteases and their inhibitors via lamellar granules into the extracellular space.

The dermis is the deepest layer of the skin and provides structural support for the skin. This layer is anchored to the epithelium by the basement membrane, a multilayered structure forming the dermo-epidermal junction. The dermis consists in fibroblasts, which produce collagen, elastin, fibrillin and structural proteoglycans, together with immunocompetent mast cells and macrophages. Collagen fibers constitute $70 \%$ of the dermis, providing strength and toughness. Elastin maintains normal elasticity and flexibility, whereas proteoglycans provide viscosity and hydration. The fibrous tissue of the dermis anchors blood and lymphatic vessels, nervous cells and fibers, sweat and sebaceous glands, follicles and small quantities of striated muscle. The subcutis or hypodermis, which is made up of a loose connective tissue layer and is an important depot of fat, lies below the dermis.

\section{Immune components of the skin}

Apart from acting as a physical barrier between the host and the environment, the skin also plays a key immunological role in sensing and responding to invading pathogens. The skin immune system can provide early innate immune responses, which promote cutaneous inflammation and adaptive immune responses that lead to an immunological memory that can recognise foreign antigens (Kupper and Fuhlbrigge 2004). A network of endogenous proteolytic enzymes and their inhibitors play an important role in this process (Yoshida 2010; Blaber et al. 2010; Beaufort et al. 2010; Sotiropoulou and Pampalakis 2010; Ohler et al. 2010).

The constitutive innate immune mechanisms in the skin consist in (1) commensal microorganisms that occupy niches suitable for bacterial growth and (2) the corneal layer comprised of dead keratinocytes and providing the physical barrier of the skin and chemical defence in the form of AMPs. In humans, such peptides include $\beta$-defensin $2, \beta$ defensin 3, cathelicidin and RNase 7, which are induced in response to infection and exert bacteriostatic or bactericidal activity against invading pathogens (Schauber and Gallo 2009). Keratinocytes that compose the deeper layers of the skin (granular, spinous and basal layers) express pattern recognition receptors. These include Toll-like receptors and nucleotide-binding oligomerisation domain proteins, which sense the pathogen-associated molecular patterns of invading microorganisms and initiate early cutaneous immune responses (Kawai and Akira 2010). In addition to keratinocytes, other cells contribute to the cutaneous immune responses, including Langerhans cells and $\gamma \delta \mathrm{T}$ cells (mice only) in the epidermis, plus macrophages, dendritic cells, mast cells, B and T cells, plasma cells, natural killer cells and fibroblasts in the dermis (Wehner et al. 2011; Tobin et al. 2011; Kupper and Fuhlbrigge 2004).

\section{Microflora of the skin}

The skin is a habitat for commensal bacteria, including Staphylococcus, Micrococcus and Corynebacterium sp., which act as a barrier against colonisation by potentially pathogenic microbes and any overgrowth of opportunistic pathogens already present on the skin. Protection is exerted passively by depleting available nutrients for competing bacteria and by preventing their adherence and/or translocation across skin layers. Invaders are also actively deterred by bacteriocin (e.g. epidermin, Pep5 and epilancin K7, bacteriocins secreted by S. epidermidis; Bastos et al. 2009) and toxic metabolites produced by commensal microflora. Finally, the pathogenicity of invading species can be tempered by degradation of their virulence factors via proteases released by commensals. In addition to providing direct protection against pathogens, commensals promote endogenous antibacterial activity by stimulating the production of AMPs via keratinocytes and by enhancing the antibody production of immune cells and bacterial clearance by local phagocytes. Commensals also help maintain inflammatory homeostasis by suppressing excess cytokine release after minor epidermal injury.

Apart from benign commensals, the human skin is often colonised by opportunistic pathogens. Among them, 
Staphylococcus aureus and Streptococcus pyogenes are the most common species. Because of the frequency of these Gram-positive bacteria on healthy skin, $S$. aureus and $S$. pyogenes are sometimes considered to be part of the normal bacterial flora of the skin. This is not the case for Gramnegative organisms such as Pseudomonas aeruginosa, Pasteurella multocida, Capnocytophaga canimorsus, Bartonella sp., Klebsiella rhinoscleromatis and Vibrio vulnificus, which are never found in the normal microflora of healthy skin and are responsible for cutaneous infections (Chiller et al. 2001).

\section{Bacterial proteases in the skin}

A variety of proteases are expressed by skin microflora, including enzymes produced by commensal species that sustain habitat homeostasis and those exploited and used as powerful virulence factors by pathogens during infection and skin injury (Fig. 1, Table 1).

\section{Role of proteases in survival and colonisation}

Commensal skin microflora and pathogenic species are both well equipped with factors that promote colonisation and persistence in the harsh conditions of the skin. A crucial step that ensures successful colonisation is bacterial adherence to the horny epidermal layer. $S$. aureus express a distinct array of receptors that recognise different human extracellular matrix proteins. These receptors are termed "microbial surface components recognising adhesive matrix molecules" (MSCRAMMs; Patti et al. 1994; Foster and Hook 1998). Microbial cell surface proteins are important virulence factors and specifically bind to extracellular matrix proteins such as fibronectin (fibronectin-binding proteins, FNBPA and FNBPB), fibrinogen (clumping factors, such as ClfA and ClfB) and collagen (collagen-binding protein). They are expressed in a coordinated and sequential fashion that depends on bacterial cell density. Regulatory loci, such as accessory gene regulator (agr) and staphylococcal accessory regulator (sar), coordinate the gene expression of most $S$. aureus MSCRAMMs and secreted proteins (Novick 2003). $S$. aureus adhesins are expressed during the early exponential growth phase, when bacterial cell density is low, whereas hemolysins, toxins and enzymes facilitating tissue destruction and dissemination, including proteases, are expressed at the end of the exponential phase and during the stationary phase of growth (Pragman and Schlievert 2004). During colonisation, staphylococcal proteases play an important role by controlling the stability and/or processing of cell surface proteins. One clear example is the proteolysis of FNBP by Ssp (V8), a staphylococcal serine protease, which decreases the adhesive phenotype of $S$. aureus and allows dissemination of the pathogen (McGavin et al. 1997).
The current paradigm suggests that tissue colonisation occurs via the formation of multicellular surface-attached agglomerations of microorganisms called "biofilm". Primary attachment of bacteria to the surface and subsequent aggregation can initiate biofilm formation, which provides resistance against many antibiotics and host defence mechanisms. In the mature biofilm, channels are formed for nutrient delivery to all biofilm cells, whereas the detachment of cell clusters can lead to the dissemination of infection. Distractive forces are crucial for both these aspects (O'Toole et al. 2000). Intracellular aggregation in biofilm is mediated by a variety of surface macromolecules, including proteins. Several lines of evidence indicate that $S$. aureus proteases are involved in the enzymatic degradation of proteinaceous biofilm formation supporting factors (Boles and Horswill 2008). The activity of $S$. aureus extracellular proteases, including the metalloprotease aureolysin (Aur) and Spl protease, has been demonstrated to be required for agr-mediated detachment in established biofilms. The targets of these agr-controlled proteases are not known but surface adhesins are likely substrates. Candidates include the surface proteins Atl, Bap and SasG, all of which play significant roles in biofilm formation (Corrigan et al. 2007; Trotonda et al. 2005; Cucarella et al. 2001; Biswas et al. 2006). Recently, the Bap protein has been identified as an Aur and SspA substrate (Martí et al. 2010). Atl is additionally known to require proteolytic processing for activation, which is inhibited by phenylmethylsulfonyl fluoride (Oshida et al. 1995). As described earlier, other possible targets of staphylococcal proteases include MSCRAMMs, which are important for adherence to the extracellular matrices of mammalian cells. Finally, the activation of lipase (Sal-1 and Sal-2) precursors by proteases secreted by $S$. aureus and the proteolytic processing of staphylococcal nucleases (Gotz et al. 1998; Suciu and Inouye 1996; Davis et al. 1977) might contribute to $S$. aureus dispersal and colonisation of new sites.

$S$. epidermidis, a common bacterial coloniser of mammalian skin, also produces exoproteases, namely cysteine (Ecp) and serine (Esp) proteases with relatively low substrate specificity (Dubin et al. 2001). The cysteine protease from $S$. epidermidis possesses the ability to cleave fibrinogen and fibronectin (Oleksy et al. 2004). Although Ecp and/or Esp have not been reported to contribute to $S$. epidermidis detachment from biofilm, these findings collectively indicate a significant contribution of proteases to bacterial dissemination via proteolytic inactivation of adhesive molecules.

The commensal lifestyle of $S$. epidermidis is partly achieved by the expression of the extracellular neutral metalloprotease SepA, which efficiently inactivates anionic AMP dermcidin (Lai et al. 2007). As part of the human skin microflora, $S$. epidermidis plays a probiotic function by preventing colonisation of more pathogenic bacteria such as $S$. aureus. 


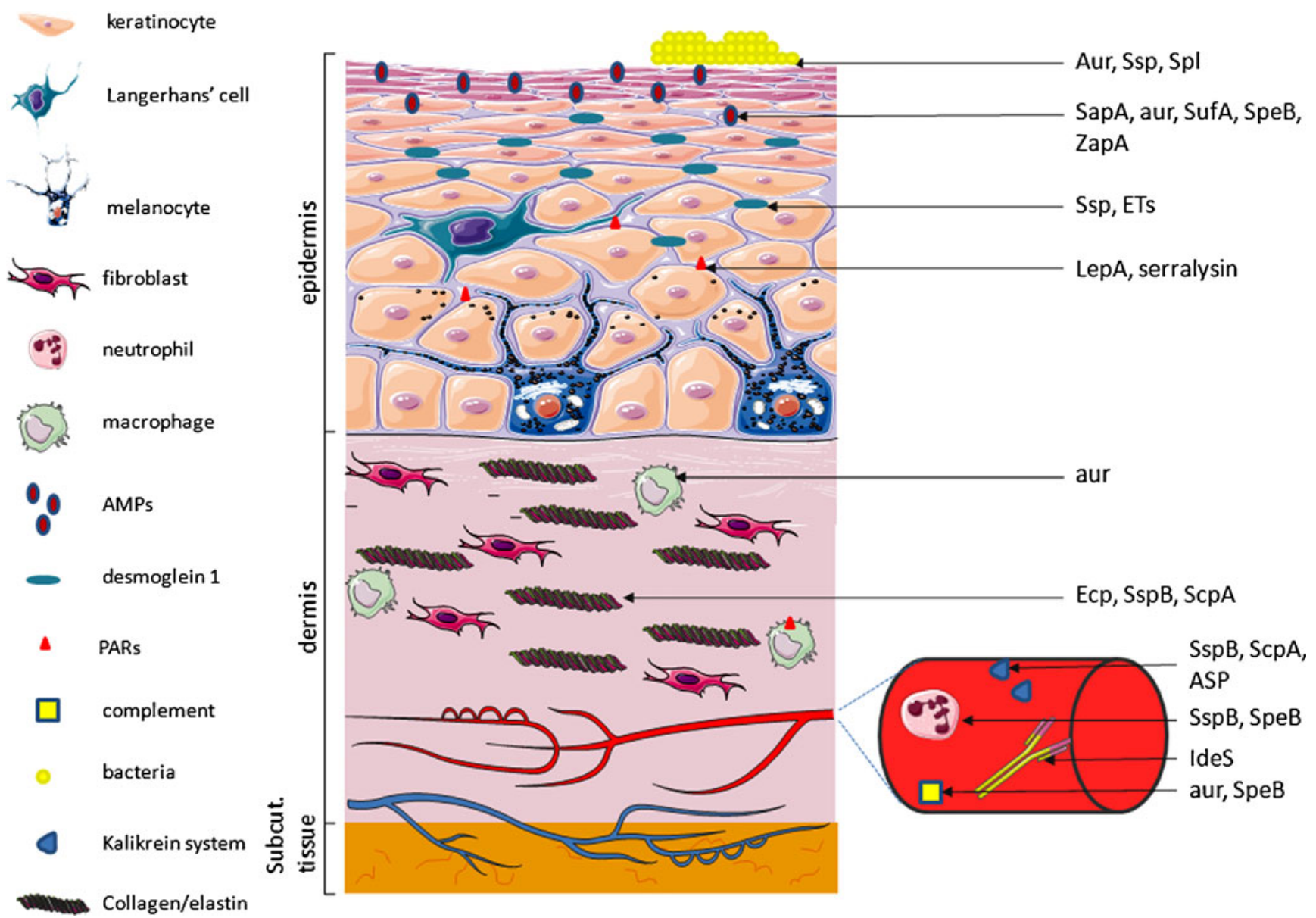

Fig. 1 Representation of some bacterial protease targets in the skin. Bacterial proteases (right) contribute to skin colonisation by microorganisms by providing nutrients and by modulating bacterial adherence properties. In epidermis, bacterial proteases can neutralise antibacterial peptides (antimicrobial peptides [AMPs], such as LL37), creating a safe niche for AMP-susceptible pathogens. The disruption of desmosomal kadherins (desmoglein 1), which provide cell-cell adhesion, causes exfoliation in the stratum granulosum. Bacterial proteolytic activity induces protease-activated receptor $(P A R)$ signalling involved in cutaneous inflammation. Pathogen penetration is facilitated by degradation of collagen and elastin, essential components of connective tissue of the dermis, by secreted bacterial proteases. Proteases produced by skin bacteria

One can argue that the SepA protease-mediated proteolytic degradation of AMP, a major determinant of innate host defence, creates a safe niche for dermicidin susceptible pathogens. Nevertheless, no evidence exists showing that S. epidermidis proteases facilitate the colonisation of the skin by other microorganisms in vivo.

S. epidermidis is a good example of the dependency of successful bacterial colonisation of the skin on the deterrence of AMP bactericidal activity. In the skin, AMPs are produced mainly by keratinocytes, neutrophils, sebocytes or sweat glands and are either expressed constitutively or after an inflammatory stimulus (Gallo and Nakatsuji 2011). In addition to exerting strong bactericidal potential by disrupting bacterial cell membranes, they can also act as potent modulate the skin immune system. Professional phagocyte functions are disabled upon bacterial proteases. Proteases may also lead to the depletion of functional neutrophils at infection sites, thus facilitating pathogen colonisation and spreading in subepithelial tissues. The cleaving of antibodies by bacterial proteases leads to the avoidance of an immunological response. Bacterial proteases target and subvert the complement system by degrading or binding complement components to prevent activation of the pathway. As potent activators of the contact system, bacterial proteases may participate in the uncontrolled generation of proinflammatory mediators, inducing an excessive inflammatory reaction, which can lead to serious tissue damage (Subcut. subcutaneous). Figures were produced using Servier Medical Art

immunomodulators. The function of defensins and cathelicidins, the best-characterised AMPs, is potentiated by AMPs derived from complement (Frick et al. 2006; Nordahl et al. 2004), haemoglobin (Mak 2008), serine proteases (Kasetty et al. 2011) or kininogen (Nordahl et al. 2005). Throughout evolution, microorganisms have developed many strategies to disable AMPs, one of them being proteolytic degradation. Despite the finding that AMPs are relatively resistant to proteolytic degradation, many skin pathogens produce proteases that can degrade human cathelicidins. Aureolysin, a metalloprotease of S. aureus, cleaves and inactivates LL-37, which might be the reason that highly proteolytic $S$. aureus strains are resistant to cathelicidin (Sieprawska-Lupa et al. 2004). S. aureus is not 


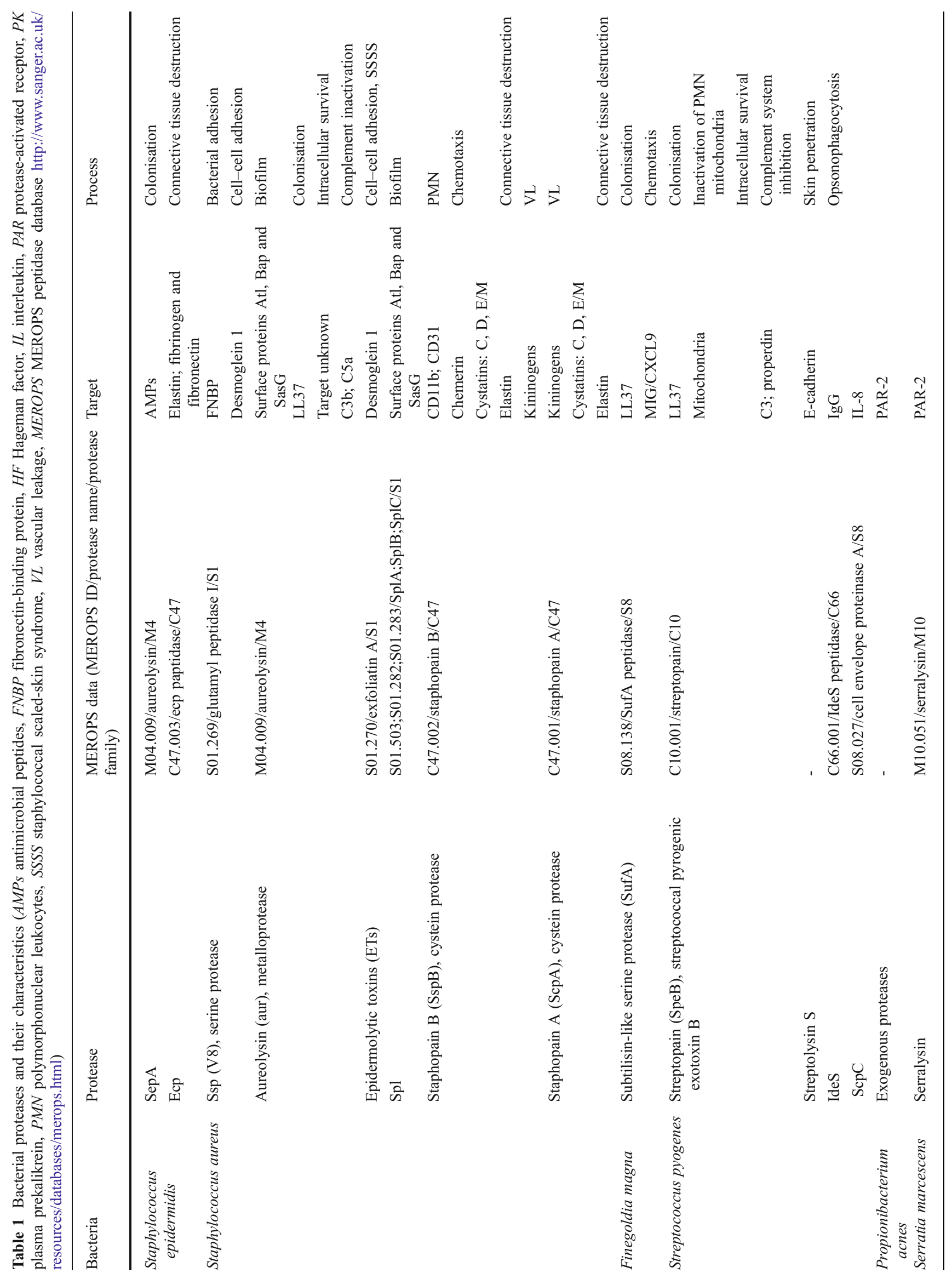




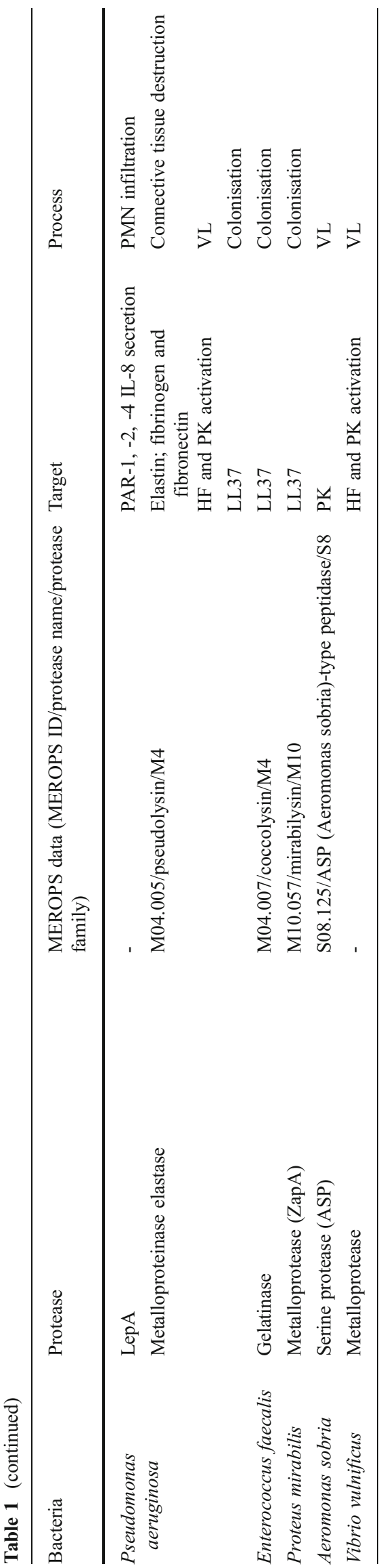

the sole pathogen that has evolved such a strategy. $S$. pyogenes is also well protected against LL-37 through an intricate mechanism involving streptopain (SpeB) expression. $\mathrm{SpeB}$, an extracellular enzyme, is concentrated in the proximity of the bacterial cell membrane in a complex with an $\alpha$ 2-macroglobulin $\left(\alpha_{2} \mathrm{M}\right)$ immobilised on the streptococcal cell surface by interacting with the GRAB protein. Despite being entrapped by $\alpha_{2} \mathrm{M}$, the enzyme is still proteolytically active against peptides, including LL-37. To reach the cell membrane, LL-37 must penetrate a layer of the $\alpha_{2} \mathrm{M}$-streptopain complex coating the bacterium where it is proteolytically degraded, allowing $S$. pyogenes to resist AMPs. Indeed, SpeB has unambiguously been demonstrated to contribute to streptococcal resistance against LL-37 in vivo in patients with severe $S$. pyogenes infections of soft tissue (Johansson et al. 2008). Similarly, the colonisation of chronic ulcers by $P$. aeruginosa, E. faecalis and $P$. mirabilis might be related to the proteolytic inactivation of LL-37 by elastase, gelatinase and metalloprotease (ZapA), respectively (Schmidtchen et al. 2002). The degradation of LL-37 by a subtilisin-like serine protease of Finegoldia magna (formerly Peptostreptococcus magnus), a commensal bacterium colonising human skin and mucous membranes, has also been documented (Karlsson et al. 2007).

The evolutionary adaptation of $S$. aureus and S. epidermidis, inhabitants of healthy human skin, to this organ chemical defence is manifested by sensing dermicidin. In response to dermicidin, the extracellular proteolytic activity of staphylococci is enhanced, resulting in proteolytic degradation of dermicidin and bacterial resistance to this antibacterial peptide (Lai et al. 2007). Since bacterial proteases can inactivate the most important chemical antimicrobial barrier in skin, namely AMPs, further invasion and penetration into the deeper skin layers is highly likely. Nevertheless, it must be stressed that none of the bacteria can penetrate intact skin and cause infection unaided. However, once the integrity of the epidermis is compromised by cuts, wounds, burns, abrasions or bites, bacterial proteases released from colonising pathogens can significantly deter the immune system and lead to further tissue damage and to bacterial dissemination and infection.

Tissue damage/injury

Bacterial proteases possess a propensity to destroy host tissue by two distinct mechanisms: direct breakage of the skin barrier, which occurs by cleavage of structural proteins in the skin, or indirect damage, which occurs following an excessive induction of the inflammatory response.

\section{Direct mechanism of proteases action}

$S$. aureus secretes exfoliative toxins, known as epidermolytic toxins (ETs), which cause blisters in bullous impetigo 
and staphylococcal scaled-skin syndrome (SSSS). Staphylococcal scalded skin syndrome is a disease that predominantly affects infants and is characterised by the loss of superficial skin layers, dehydration and secondary infections. The toxin is a serine protease of $\sim 30 \mathrm{kDa}$ characterised by a narrow substrate specificity. ET recognises and cleaves only desmoglein 1 , a desmosomal cadherin that mediates cell-cell adhesion (Amagai et al. 2002; Hanakawa et al. 2004). The target protein, desmoglein 1 , is recognised both through an interaction at the classical P1 site and via additional features in the tertiary structure, located away from the hydrolysed peptide bond. Disruption of desmoglein 1 by ETs in the deep layers of skin can be compensated by another desmoglein, desmoglein 3 . Therefore, exfoliation only occurs in the SG, in which desmoglein 3 is not present. Accordingly, the hydrolysis of desmoglein 1 (but not that of other desmogleins) by ETs has been demonstrated experimentally both in vitro and in vivo, thus elucidating the mechanism of ET-induced epidermolysis (Amagai et al. 2000; Hanakawa et al. 2002). The toxin can spread through the bloodstream and therefore not all lesions are infected. Overall, the destruction of the epidermal barrier facilitates efficient progression of the infection. Three exfoliative toxins (ET), namely A, B and D, encoded by eta, etb and etd, respectively, have been identified (Lee et al. 1987). ETAproducing strains dominate Europe, USA and Africa (de Azavedo and Arbuthnott 1981). Expression of both eta and etb is regulated by agr (Sheehan et al. 1992).

The $S$. aureus extracellular serine protease, glutamylendopeptidase SspA, commonly referred to as V8 protease, is also regulated by the $a g r$ system. SspA preferentially cleaves peptide bonds with glutamate (and aspartate, to a lesser extent) at the carboxy-terminal side (Ono et al. 2010). Interestingly, the SspA protease shows sequence similarity to exfoliative toxins and shares a similar specificity of glutamate-specific cleavage (Dubin 2002). Recently, SspA has been reported to impair the epidermal permeability barrier in nude mice by disturbing the structure of the SC but does not cause epidermal hyperproliferation and inflammatory infiltration. Evaluation of SspA-induced injury in hairless mice with normal immune systems has confirmed results obtained when nude mice are used as a model of infection (Hirasawa et al. 2010). Furthermore, analysis by scanning electron microscopy has shown a reduced abundance of adhesive corneocytes on the skin of mice on which protease is applied. Based on the high degree of similarity between the primary and tertiary SspA structures and the preference of exfoliative toxins for Glu-Xaa peptide bonds, one can speculate that the epidermal permeability is the consequence of desmoglein 1 cleavage in corneodesmosomes. Disruption of the epithelial barrier by $S$. aureus extracellular protease compromises the protective functions of the skin by allowing the entry of allergens and microorganisms. A similar effect has been reported for a cysteine protease of house-dust mites, which impairs the epidermal permeability barrier, thus enhancing $\operatorname{IgE}$ and IgG responses to penetrating allergens (Kato et al. 2005; Kikuchi et al. 2006; Nakamura et al. 2006). This can additionally aggravate allergic reactions attributable to mast cell activation by infection (McAlpine et al. 2011). Notably, in this context, $S$. aureus can subvert the extracellular antimicrobial activity of mast cells by promoting its own internalisation by these cells (Abel et al. 2011).

Once proteolytic enzymes produced by skin pathogens disrupt the keratynocyte barrier, the underlying tissue layers can be penetrated by microorganisms and their products. Recently, the translocation of S. pyogenes (Group A streptococcus, GAS) through damaged skin has been documented as being facilitated by streptolysin S. This process is accompanied by the cleavage of transmembrane junctional proteins, including E-cadherin. Interestingly, streptolysin acts in concert with calpain, the host cysteine protease (Sumitomo et al. 2011).

Elastin is one of the connective tissue components of the dermis layer. $S$. aureus secretes two papain-like cysteine proteases, namely staphopain A (ScpA) and staphopain B (SspB). ScpA exerts elastinolytic activity comparable with neutrophil elastase, which might explain the destruction of connective tissue during staphylococcal infection (Potempa et al. 1988). Furthermore, recent studies indicate that the presence of staphopains at concentrations as low as $10 \mathrm{nM}$ can also degrade collagen (Ohbayashi et al. 2010). S. epidermidis, a predominant inhabitant of human skin, express a cell-wall-associated cysteine protease Ecp. A homology search by using the N-terminal sequence has revealed sequence similarity to $S$. aureus ScpA and SspB. Consistent with this, the Ecp protease also possesses elastinolytic activity, which might contribute to the invasiveness and pathogenic potential of S. epidermidis (Oleksy et al. 2004).

Elastase, the major metalloproteinase expressed by $P$. aeruginosa, degrades proteins on the surface of skinderived fibroblasts. Moreover, this enzyme can inhibit fibroblast cell growth. These effects, in conjunction with ex vivo data showing that elastase is present in the fluids of wounds infected with $P$. aeuginosa, suggest that bacterial proteinases play a pathogenic role in chronic ulcers (Schmidtchen et al. 2003).

Bacterial enzymes also contribute indirectly to tissue injury by intercepting the functions of tightly regulated host enzymes. Alternatively, they can release the activity of endogenous proteases from the control exerted by proteinase inhibitors, including cystatins and elafin (Vincents et al. 2007; Guyot et al. 2010). Cystatins regulate skin barrier formation by inhibiting the activity of cathepsin V, cathepsin $\mathrm{L}$ and legumain, thereby controlling transglutaminase 3 processing. Infringement of this pathway leads to abnormal 
SC and hair follicle formation and a severe malfunction of the skin barrier probably contributes to the dysregulation observed in inflammatory dermatoses (Cheng et al. 2009). S. aureus cysteine proteases ScpA and SspB are not inhibited by human cystatins; instead, extracellular cystatins C, D and $\mathrm{E} / \mathrm{M}$ are hydrolysed by both staphopains (Vincents et al. 2007). Thus, the normal activity of the cystatins is downregulated, indicating that bacterial enzymes can alter the host protease-inhibitor balance. Moreover, the inactivation of cystatins can lead to the enhancement of cathepsin activity, which in turn can inactivate AMPs. Despite a broad range of in vitro and ex vivo results demonstrating the pathogenic potential of staphopains, their role as important staphylococcal virulence factors in vivo still needs to be demonstrated by using appropriate animal models of $S$. aureus infection.

\section{Indirect mechanism of proteases action}

The host defence system has to cope with various microorganisms to obtain equilibrium, otherwise an exacerbated inflammatory response can lead to tissue injury. Penetration of bacteria through the skin barrier mobilises a broad range of host defence mechanisms, such as professional phagocytes, the complement system and cytokines. Since bacteria proteases possess the ability to inactivate, derail or interfere with these defence mechanisms, they are considered to be potential virulence factors.

Professional phagocytes Cellular defence involves neutrophils and macrophages that infiltrate subepithelial connective tissues. The critical step that precedes bacterial engulfment is the recognition of pathogens. The efficiency of this step is enhanced by bacteria opsonisation with specific antibodies and/or complements. IdeS is a cysteine protease of $S$. pyogenes that allows GAS to evade antibody-mediated phagocytosis by cleaving $\operatorname{IgG}$ at the lower hinge region. Simultanously, IgGs captured via their Fc region by immunoglobulin-binding proteins, streptococcal $\mathrm{M}$ or M-like proteins on bacterial surfaces are protected from proteolysis; this allows the formation of a host-like coat by IgG molecules ( $\mathrm{Su}$ et al. 2011). Interestingly, cystatin $\mathrm{C}$, a cysteine protease inhibitor, acts as a cofactor that accelerates IgG cleavage by IdeS (Vincents et al. 2008). Another strategy aimed at professional phagocytes involves the use of streptopain (streptococcal pyrogenic exotoxin B, SpeB) by S. pyogenes (Nelson et al. 2011). SpeB internalised by neutrophils can cause mitochondrial damage manifested by a decrease in dehydrogenase activity and a loss of membrane potential after $\mathrm{r}-\mathrm{SpeB}$ treatment. Although the incubation of neutrophils with the wild-type strain, the speB mutant, or the r-SpeB protein does not affect the total number of viable cells, one can argue that professional phagocyte functions are disabled (Chiang-Ni et al. 2006).

A significant reduction in the number of functional phagocytes at infection sites can be potentially induced by SspB, the cysteine protease of $S$. aureus. This effect is exerted by selective cleavage of $\mathrm{CD} 11 \mathrm{~b}$ on phagocytes, which rapidly acquire the features of a dead cell (Smagur et al. 2009a). Furthermore, exposure of phagocytes to SspB blocks the phagocytosis of $S$. aureus by neutrophils, represses their chemotactic activity and induces extensive non-phlogistic clearance of SspB-treated cells by macrophages. The latter effect occurs by the proteolytic degradation of CD31, which constitutes a repulsive "do not-eat-me" signal on the surface of leucocytes (Smagur et al. 2009b). Collectively, this may lead to the depletion of functional neutrophils at infection sites, thus facilitating staphylococcal colonisation and spreading in subepithelial tissues.

The intracellular persistence of pathogens in both professional phagocytes and non-phagocyting cells is supported by the expression of bacterial proteases. An S. aureus metalloprotease, aureolysin, contributes to survival within macrophages (Kubica et al. 2008). Following phagocytosis by human neutrophils, aureolysin is strongly expressed by engulfed $S$. aureus, thereby confirming enzyme production during host-pathogen interaction (Burlak et al. 2007). Additionally, in vivo, SpeB appears to contribute to the intracellular survival of $S$. pyogenes in macrophages during acute invasive infections (Thulin et al. 2006). Together, the data make it clear that bacterial proteases can play a role in protecting bacteria from phagocytes in skin layers infiltrated by these immune cells.

Complement system The complement system participates in the immune recognition of foreign antigens, many of which might penetrate the skin by physical injury or transcutaneous adsorption. Pathogens target and subvert the complement system by degrading or binding complement components to prevent the activation of the pathway. Since the $\mathrm{C} 3$ and $\mathrm{C} 5$ convertase complexes play a pivotal role in activating the complement system, they are the major targets of many bacterial proteases (Potempa and Pike 2009).

Recent data indicate that $S$. aureus aureolysin disables complement activation by inhibiting the deposition of $\mathrm{C} 3 \mathrm{~b}$ on the bacterial surface and the release of the chemoattractant $\mathrm{C} 5 \mathrm{a}$, practically paralysing all complement-dependent antibacterial functions. This occurs because aureolysin cleaves $\mathrm{C} 3$, the central complement protein, generating $\mathrm{C} 3 \mathrm{~b}$, which is further degraded by host factors. Thus, aureolysin acts in synergy with host regulators to inactivate C3, effectively dampening the host immune response (Laarman et al. 2011). Another skin pathogen, S. pyogenes, prevents the formation of the C5 convertase complex, since SpeB efficiently degrades C3 (Kuo et al. 2008; Terao et al. 2008). 
SpeB protease also cleaves properdin, which stabilises the formation of the $\mathrm{C} 5$ convertase complex through an alternative complement activation pathway (Tsao et al. 2006). Finally, a specific S. pyogenes enzyme, C5a peptidase (Wexler et al. 1985), disables the complement-dependent influx of neutrophils to sites infected with $S$. pyogenes. C5 peptidase strongly contributes to $S$. pyogenes pathogenicity (Ji et al. 1996, 1997; Cleary et al. 2004) and might be essential for protecting streptococci during skin infections. Interestingly, C5a peptidase expression is upregulated in bacteria by human serum (Gleich-Theurer et al. 2009).

Cytokine and chemokine network Chemokines are a large superfamily of cytokines that provide chemotactic activity for immune cells. Modulation of their activity can occur upon proteolytic processing at both $\mathrm{N}$ - and C-termini. Some bacterial species, such as $S$. pyogenes, use proteases to exploit this mechanism. The $S$. pyogenes protease $\mathrm{ScpC}$ degrades interleukin-8 (IL-8), a chemokine that mediates neutrophil transmigration and activation. Bacteria expressing $\mathrm{ScpC}$ overcome immune clearance by preventing the recruitment of neutrophils to soft tissue infection in mice (Sjölinder et al. 2008). Finegoldia magna, a commensal that is also associated with skin and soft tissue infections, express subtilisin-like extracellular serine protease (SufA). SufA is associated with the bacterial cell surface but is also released in substantial amounts during bacterial growth. SufA has been found to cleave and inactivate the CXC chemokine MIG/CXCL9 efficiently, indicating that the enzyme promotes $F$. magna survival and colonisation (Karlsson et al. 2007). Recently, serine proteases derived from $S$. aureus have been found to initiate and maintain the inflammatory response by modulating IL-8 synthesis and nuclear factor kappa B (NFkB) activation (Rudack et al. 2009). A similar effect, i.e. induction of IL-8 secretion, has also been documented for $P$. aeruginosa exoprotease LepA (Kida et al. 2008).

Chemerin is a ligand for CMKLR1, a seven transmembrane G-protein-coupled receptor. Chemerin circulates as an inactive precursor (prochemerin) in blood but its cytokine expression (specific mRNA) has also been detected in skin (Wittamer et al. 2003). Maturation of chemerin into an active cytokine requires proteolytic processing. Recently, active chemerin has been demonstrated to be generated by the secreted cysteine protease SspB of $S$. aureus (Kulig et al. 2007). In skin infected with $S$. aureus, proteolytically processed chemerin might therefore contribute to the pathological inflammatory response by attracting selected immunoregulatory antigen-presenting cells, such as immature plasmacytoid dendritic cells (Skrzeczyńska-Moncznik et al. 2009) and macrophages. The potential in vivo role of staphopain in chemerin activation correlates with the finding that $S$. aureus has been implicated as an aggravating factor in psoriasis (Kulig et al. 2007). Consistent with this, high levels of active chemerin have been found in the skin of psoriatic patients (Skrzeczyńska-Moncznik et al. 2009).

Cell signalling The protease-activated receptors (PARs) are a family of four G-protein-coupled receptors that are activated upon enzymatic cleavage at their N-termini by specific serine proteases. The exposed tethered ligand domains bind to and activate the cleaved receptors. Four human members of the family are known: PAR1-4. PAR-1, PAR3 and PAR- 4 are activated physiologically by thrombin, whereas PAR-2 activation is associated with a proinflammatory response. PAR-2 is highly expressed in keratinocytes and might play an important role in cutaneous inflammation. PARs are targeted by many bacteria-derived proteases (Imamura and Potempa 2011), including enzymes produced by skin pathogens. LepA, a secreted protease from $P$. aeruginosa, signals through PAR-1-, PAR-2- and PAR-4-specific proteolysis and activates the NFKB pathway (Kida et al. 2008). Simultaneously, LasB, an elastynolytic metalloprotease from the same bacterium, antagonises the effect of LepA by degrading and inactivating the receptor (Dulon et al. 2005). Serratia marcescens, a rare cause of skin infections, expresses serralysin, which cleaves PAR-2 on HeLa cells. This leads to the activation of critical transcription factors AP-1, C/EBP $\beta$ and NFKB (Kida et al. 2007). Recently, exogenous proteases from Propionibacterium acnes have been demonstrated to elicit cellular responses via PAR2. Activation of PAR-2 on keratinocytes has been shown to lead to the induction of proinflammatory cytokines, AMPs and matrix metalloproteinases (Lee et al. 2010).

Kallikrein/kinin system The contact system is an integral part of skin innate immunity, which, once activated, delivers bactericidal peptides derived from kininogens, entraps bacteria and stimulates professional phagocytes. Furthermore, kinins, such as bradykinin (BK) and its metabolite, desArg9BK, can act as co-mitogens in cellular proliferation and as proinflammatory factors, which are important for vascular permeabilisation and pain propagation (SchremmerDanninger et al. 1999).

Initially, vascular leakage (VL) supplies antimicrobial factors (e.g. antibodies, complement factors) and causes blood leucocyte infiltration, contributing to pathogen elimination. An excessive inflammatory reaction, a consequence of serious tissue damage, can be induced by bacterial proteases, which play a crucial role in the uncontrolled generation of proinflammatory mediators. Activation of the kallikrein-kinin system is initiated by Hageman factor (HF) activation, followed by the production of kallikrein from plasma prekallikrein (PK). High molecular weight kininogen is the substrate for plasma kallikrein, which releases BK. On the other hand, kallidin is generated from 
low-molecular weight kininogen by tissue kallikrein (Chao et al. 2010). Kallidinis are ultimately converted to BK (Cochrane and Griffin 1982; Bhoola et al. 1992).

Bacterial proteases are potent activators of contact system zymogens (Herwald and Potempa 2011). Alkaline proteinase and elastase from $P$. aeruginosa and metalloproteases from $V$. vulnificus activate HF and PK (Molla et al. 1989); however, only the latter has been described in the human (Miyoshi and Shinoda 1992). Aeromonas sobria, a facultative anaerobe that can cause skin infections, expresses serine proteases (ASP) that induce vascular leakage activity by specifically activating human PK (Jones and Wilcox 1995; Imamura et al. 2006).

The release of kinins requires the cleavage of kininogen at two peptide bonds; this can be achieved directly by bacterial proteases without PK or HF activation. Bacterial proteases, such as staphopains from $S$. aureus or streptopain from $S$. pyogenes, are important virulence factors, since they can potently release kinins from kininogens (Imamura et al. 2005; Herwald et al. 1996). Proteolytically active ScpA has been found to induce VL in a BK B(2)-receptor-dependent manner in guinea pig skin. This effect is augmented by SspB, which, by itself, has no VL activity (Imamura et al. 2005). The enhancing effect of SspB is attributable to the release of a new kinin that contains an amino terminus that is extended by three amino acid residues. Furthermore, plasma leakage spreads in subcutaneous tissue, since ScpB degrades elastin and other extracellular matrix proteins (Potempa et al. 1988). A similar mode of action has been reported for serine protease ASP secreted by $A$. sobria, which induces VL activity mainly in a $\mathrm{BK} \mathrm{B}(2)$ receptor-dependent manner in guinea pig skin. ASP produces more VL activity directly from human lowmolecular-weight kininogen than from high-molecularweight kininogen (Imamura et al. 2006). Furthermore, ASP produces far more desArg-BK than BK from kininogens. DesArg-BK binds to the $\mathrm{B} 1$ receptor and responses mediated by this receptor are upregulated by lipopolysaccharide or inflammatory cytokines in animal and human tissues (Marceau et al. 1998). Collectively, the data clearly show that bacterial proteases play an important role in the amplification of kinin generation, which can be associated with the pathophysiology of infectious diseases. Such tactics can facilitate systemic dissemination of a pathogen from the initial site of colonisation.

\section{Concluding remarks}

Taken together, the above data clearly reveal that proteases secreted by pathogenic bacteria that colonise damaged skin play a role in the invasion of deeper skin layers and contribute to the development of a local inflammatory reaction.
This function is in stark contrast to proteases of skin commensal microorganisms, which use their proteases to maintain an equilibrium with host defences and homeostasis of the colonised skin.

Open Access This article is distributed under the terms of the Creative Commons Attribution License, which permits any use, distribution and reproduction in any medium, provided the original author(s) and the source are credited.

\section{References}

Abel J, Goldmann O, Ziegler C, Höltje C, Smeltzer MS, Cheung AL, Bruhn D, Rohde M, Medina E (2011) Staphylococcus aureus evades the extracellular antimicrobial activity of mast cells by promoting its own uptake. J Innate Immun 3:495-507

Amagai M, Matsuyoshi N, Wang ZH, Andl C, Stanley JR (2000) Toxin in bullous impetigo and staphylococcal scalded-skin syndrome targets desmoglein 1. Nat Med 6:1275-1277

Amagai M, Yamaguchi T, Hanakawa Y, Nishifuji K, Sugai M, Stanley JR (2002) Staphylococcal exfoliative toxin B specifically cleaves desmoglein 1. J Invest Dermatol 118:845-850

Azavedo J de, Arbuthnott JP (1981) Prevalence of epidermolytic toxin in clinical isolates of Staphylococcus aureus. J Med Microbiol 14:341-344

Bastos MC, Ceotto H, Coelho ML, Nascimento JS (2009) Staphylococcal antimicrobial peptides: relevant properties and potential biotechnological applications. Curr Pharm Biotechnol 10:38-61

Beaufort N, Plaza K, Utzschneider D, Schwarz A, Burkhart JM, Creutzburg S, Debela M, Schmitt M, Ries C, Magdolen V (2010) Interdependence of kallikrein-related peptidases in proteolytic networks. Biol Chem 391:581-587

Bhoola KD, Figueroa CD, Worthy K (1992) Bioregulation of kinins: kallikreins, kininogens, and kininases. Pharmacol Rev 44:1-80

Biswas R, Voggu L, Simon UK, Hentschel P, Thumm G, Götz F (2006) Activity of the major staphylococcal autolysin Atl. FEMS Microbiol Lett 259:260-268

Blaber M, Yoon H, Juliano MA, Scarisbrick IA, Blaber SI (2010) Functional intersection of the kallikrein-related peptidases (KLKs) and thrombostasis axis. Biol Chem 391:311-320

Boles BR, Horswill AR (2008) Agr-mediated dispersal of Staphylococcus aureus biofilms. PLoS Pathog 4:e1000052

Burlak C, Hammer CH, Robinson MA, Whitney AR, McGavin MJ, Kreiswirth BN, Deleo FR (2007) Global analysis of communityassociated methicillin-resistant Staphylococcus aureus exoproteins reveals molecules produced in vitro and during infection. Cell Microbiol 9:1172-1190

Candi E, Schmidt R, Melino G (2005) The cornified envelope: a model of cell death in the skin. Nat Rev Mol Cell Biol 6:328-340

Chao J, Shen B, Gao L, Xia CF, Bledsoe G, Chao L (2010) Tissue kallikrein in cardiovascular, cerebrovascular and renal diseases and skin wound healing. Biol Chem 391:345-355

Cheng T, Tjabringa GS, Vlijmen-Willems IM van, Hitomi K, Erp PE van, Schalkwijk J, Zeeuwen PL (2009) The cystatin M/E-controlled pathway of skin barrier formation: expression of its key components in psoriasis and atopic dermatitis. Br J Dermatol 161:253-264

Chiang-Ni C, Wang CH, Tsai PJ, Chuang WJ, Lin YS, Lin MT, Liu CC, Wu JJ (2006) Streptococcal pyrogenic exotoxin B causes mitochondria damage to polymorphonuclear cells preventing 
phagocytosis of group A streptococcus. Med Microbiol Immunol 195:55-63

Chiller K, Selkin BA, Murakawa GJ (2001) Skin microflora and bacterial infections of the skin. J Invest Dermatol Symp Proc 6:170-174

Cleary PP, Matsuka YV, Huynh T, Lam H, Olmsted SB (2004) Immunization with $\mathrm{C} 5$ a peptidase from either group A or B streptococci enhances clearance of group A streptococci from intranasally infected mice. Vaccine 22:4332-4341

Cochrane CG, Griffin JH (1982) The biochemistry and pathophysiology of the contact system of plasma. Adv Immunol 33:241-306

Corrigan RM, Rigby D, Handley P, Foster TJ (2007) The role of Staphylococcus aureus surface protein SasG in adherence and biofilm formation. Microbiology 153:2435-2446

Cucarella C, Solano C, Valle J, Amorena B, Lasa I, Penadés JR (2001) Bap, a Staphylococcus aureus surface protein involved in biofilm formation. J Bacteriol 183:2888-2896

Davis A, Moore IB, Parker DS, Taniuchi H (1977) Nuclease B. A possible precursor of nuclease A, an extracellular nuclease of Staphylococcus aureus. J Biol Chem 252:6544-6553

Dubin G (2002) Extracellular proteases of Staphylococcus spp. Biol Chem 383:1075-1086

Dubin G, Chmiel D, Mak P, Rakwalska M, Rzychon M, Dubin A (2001) Molecular cloning and biochemical characterisation of proteases from Staphylococcus epidermidis. Biol Chem 382:1575-1582

Dulon S, Leduc D, Cottrell GS, D'Alayer J, Hansen KK, Bunnett NW, Hollenberg MD, Pidard D, Chignard M (2005) Pseudomonas aeruginosa elastase disables proteinase-activated receptor 2 in respiratory epithelial cells. Am J Respir Cell Mol Biol 32:411-419

Foster TJ, Hook M (1998) Surface protein adhesins of Staphylococcus aureus. Trends Microbiol 6:484-488

Frick IM, Akesson P, Herwald H, Mörgelin M, Malmsten M, Nägler DK, Björck L (2006) The contact system - a novel branch of innate immunity generating antibacterial peptides. EMBO J 25:5569-5578

Gallo RL, Nakatsuji T (2011) Microbial symbiosis with the innate immune defense system of the skin. J Invest Dermatol 131:1974-1980

Gleich-Theurer U, Aymanns S, Haas G, Mauerer S, Vogt J, Spellerberg B (2009) Human serum induces streptococcal c5a peptidase expression. Infect Immun 77:3817-3825

Gotz F, Verheij HM, Rosenstein R (1998) Staphylococcal lipases: molecular characterisation, secretion, and processing. Chem Phys Lipids 93:15-25

Guyot N, Bergsson G, Butler MW, Greene CM, Weldon S, Kessler E, Levine RL, O'Neill SJ, Taggart CC, McElvaney NG (2010) Functional study of elafin cleaved by Pseudomonas aeruginosa metalloproteinases. Biol Chem 391:705-716

Hanakawa Y, Schechter NM, Lin C, Garza L, Li H, Yamaguchi T, Fudaba Y, Nishifuji K, Sugai M, Amagai M, Stanley JR (2002) Molecular mechanisms of blister formation in bullous impetigo and staphylococcal scalded skin syndrome. J Clin Invest 110:53-60

Hanakawa Y, Schechter NM, Lin C, Nishifuji K, Amagai M, Stanley JR (2004) Enzymatic and molecular characteristics of the efficiency and specificity of exfoliative toxin cleavage of desmoglein 1. J Biol Chem 279:5268-5277

Herwald H, Potempa J (2011) Kinins in bacterial infections. In: Bader M (ed) Kinins. de Gruyter, Berlin, pp 307-320

Herwald H, Collin M, Müller-Esterl W, Björck L (1996) Streptococcal cysteine proteinase releases kinins: a virulence mechanism. J Exp Med 184:665-673

Hirasawa Y, Takai T, Nakamura T, Mitsuishi K, Gunawan H, Suto H, Ogawa T, Wang XL, Ikeda S, Okumura K, Ogawa H (2010) Staphylococcus aureus extracellular protease causes epidermal barrier dysfunction. J Invest Dermatol 130:614-617
Imamura T, Potempa J (2011) Microbial proteases: relevance to the inflammatory response. In: Vergnolle $\mathrm{N}$, Chignard $\mathrm{M}$ (eds) Proteases and their receptors in inflammation. Springer, Berlin Heidelberg New York, pp 275-290

Imamura T, Tanase S, Szmyd G, Kozik A, Travis J, Potempa J (2005) Induction of vascular leakage through release of bradykinin and a novel kinin by cysteine proteinases from Staphylococcus aureus. J Exp Med 201:1669-1676

Imamura T, Kobayashi H, Khan R, Nitta H, Okamoto K (2006) Induction of vascular leakage and blood pressure lowering through kinin release by a serine proteinase from Aeromonas sobria. J Immunol 177:8723-8729

Ji Y, McLandsborough L, Kondagunta A, Cleary PP (1996) C5a peptidase alters clearance and trafficking of group A streptococci by infected mice. Infect Immun 64:503-510

Ji Y, Carlson B, Kondagunta A, Cleary PP (1997) Intranasal immunization with C5a peptidase prevents nasopharyngeal colonization of mice by the group A Streptococcus. Infect Immun 65:2080-2087

Johansson L, Thulin P, Sendi P, Hertzén E, Linder A, Akesson P, Low DE, Agerberth B, Norrby-Teglund A (2008) Cathelicidin LL-37 in severe Streptococcus pyogenes soft tissue infections in humans. Infect Immun 76:3399-3404

Jones BL, Wilcox MH (1995) Aeromonas infections and their treatment. J Antimicrob Chemother 35:453-461

Karlsson C, Andersson ML, Collin M, Schmidtchen A, Björck L, Frick IM (2007) SufA-a novel subtilisin-like serine proteinase of Finegoldia magna. Microbiology 153:4208-4218

Kasetty G, Papareddy P, Kalle M, Rydengård V, Walse B, Svensson B, Mörgelin M, Malmsten M, Schmidtchen A (2011) The C-terminal sequence of several human serine proteases encodes host defense functions. J Innate Immun 3:471-482

Kato T, Takai T, Mitsuishi K, Okumura K, Ogawa H (2005) Cystatin A inhibits IL-8 production by keratinocytes stimulated with Der $\mathrm{p} 1$ and Der f 1: biochemical skin barrier against mite cysteine proteases. J Allergy Clin Immunol 116:169-176

Kawai T, Akira S (2010) The role of pattern-recognition receptors in innate immunity: update on Toll-like receptors. Nat Immunol 11:373-384

Kawakubo T, Yasukochi A, Okamoto K, Okamoto Y, Nakamura S, Yamamoto K (2011) The role of cathepsin E in terminal differentiation of keratinocytes. Biol Chem 392:571-585

Kida Y, Inoue H, Shimizu T, Kuwano K (2007) Serratia marcescens serralysin induces inflammatory responses through proteaseactivated receptor 2. Infect Immun 75:164-174

Kida Y, Higashimoto Y, Inoue H, Shimizu T, Kuwano K (2008) A novel secreted protease from Pseudomonas aeruginosa activates NF-kappaB through protease-activated receptors. Cell Microbiol 10:1491-1504

Kikuchi Y, Takai T, Kuhara T, Ota M, Kato T, Hatanaka H, Ichikawa S, Tokura T, Akiba H, Mitsuishi K, Ikeda S, Okumura K, Ogawa H (2006) Crucial commitment of proteolytic activity of a purified recombinant major house dust mite allergen Der $\mathrm{p} 1$ to sensitization toward IgE and IgG responses. J Immunol 177:1609-1617

Kubica M, Guzik K, Koziel J, Zarebski M, Richter W, Gajkowska B, Golda A, Maciag-Gudowska A, Brix K, Shaw L, Foster T, Potempa J (2008) A potential new pathway for Staphylococcus aureus dissemination: the silent survival of S. aureus phagocytosed by human monocyte-derived macrophages. PLoS One 3:e1409

Kulig P, Zabel BA, Dubin G, Allen SJ, Ohyama T, Potempa J, Handel TM, Butcher EC, Cichy J (2007) Staphylococcus aureus-derived staphopain B, a potent cysteine protease activator of plasma chemerin. J Immunol 178:3713-3720

Kuo CF, Lin YS, Chuang WJ, Wu JJ, Tsao N (2008) Degradation of complement 3 by streptococcal pyrogenic exotoxin B inhibits complement activation and neutrophil opsonophagocytosis. Infect Immun 76:1163-1169 
Kupper TS, Fuhlbrigge RC (2004) Immune surveillance in the skin: mechanisms and clinical consequences. Nat Rev Immunol 4:211-222

Laarman AJ, Ruyken M, Malone CL, van Strijp JA, Horswill AR, Rooijakkers SH (2011) Staphylococcus aureus metalloprotease aureolysin cleaves complement $\mathrm{C} 3$ to mediate immune evasion. J Immunol 186:6445-6453

Lai Y, Villaruz AE, Li M, Cha DJ, Sturdevant DE, Otto M (2007) The human anionic antimicrobial peptide dermcidin induces proteolytic defence mechanisms in staphylococci. Mol Microbiol 63:497-506

Lee CY, Schmidt JJ, Johnson-Winegar AD, Spero L, Iandolo JJ (1987) Sequence determination and comparison of the exfoliative toxin A and toxin B genes from Staphylococcus aureus. J Bacteriol 169:3904-3909

Lee SE, Kim JM, Jeong SK, Jeon JE, Yoon HJ, Jeong MK, Lee SH (2010) Protease-activated receptor-2 mediates the expression of inflammatory cytokines, antimicrobial peptides, and matrix metalloproteinases in keratinocytes in response to Propionibacterium acnes. Arch Dermatol Res 302:745-756

Mak P (2008) Hemocidins in a functional and structural context of human antimicrobial peptides. Front Biosci 13:6859-6871

Marceau F, Hess JF, Bachvarov DR (1998) The B1 receptors for kinins. Pharmacol Rev 50:357-386

Martí M, Trotonda MP, Tormo-Más MA, Vergara-Irigaray M, Cheung AL, Lasa I, Penadés JR (2010) Extracellular proteases inhibit protein-dependent biofilm formation in Staphylococcus aureus. Microbes Infect 12:55-64

McAlpine SM, Enoksson M, Lunderius-Andersson C, Nilsson G (2011) The effect of bacterial, viral and fungal infection on mast cell reactivity in the allergic setting. J Innate Immun 3:120-130

McGavin MJ, Zahradka C, Rice K, Scott JE (1997) Modification of the Staphylococcus aureus fibronectin binding phenotype by V8 protease. Infect Immun 65:2621-2628

Miyoshi S, Shinoda S (1992) Activation mechanism of human Hageman factor-plasma kallikrein-kinin system by Vibrio vulnificus metalloprotease. FEBS Lett 308:315-319

Molla A, Yamamoto T, Akaike T, Miyoshi S, Maeda H (1989) Activation of hageman factor and prekallikrein and generation of kinin by various microbial proteinases. J Biol Chem 264:10589-10594

Nakamura T, Hirasawa Y, Takai T, Mitsuishi K, Okuda M, Kato T, Okumura K, Ikeda S, Ogawa H (2006) Reduction of skin barrier function by proteolytic activity of a recombinant house dust mite major allergen Der f 1. J Invest Dermatol 126:2719-2723

Nelson DC, Garbe J, Collin M (2011) Cysteine proteinase SpeB from Streptococcus pyogenes - a potent modifier of immunologically important host and bacterial proteins. Biol Chem 392:1077-1088

Nordahl EA, Rydengård V, Nyberg P, Nitsche DP, Mörgelin M, Malmsten M, Björck L, Schmidtchen A (2004) Activation of the complement system generates antibacterial peptides. Proc Natl Acad Sci USA 101:16879-16884

Nordahl EA, Rydengård V, Mörgelin M, Schmidtchen A (2005) Domain 5 of high molecular weight kininogen is antibacterial. J Biol Chem 280:34832-34839

Novick RP (2003) Autoinduction and signal transduction in the regulation of staphylococcal virulence. Mol Microbiol 48:1429-1449

Ohbayashi T, Irie A, Murakami Y, Nowak M, Potempa J, Nishimura Y, Shinohara M, Imamura T (2010) Degradation of fibrinogen and collagen by staphopains, cysteine proteases released from Staphylococcus aureus. Microbiology 157:786-792

Ohler A, Debela M, Wagner S, Magdolen V, Becker-Pauly C (2010) Analyzing the protease web in skin: meprin metalloproteases are activated specifically by KLK4, 5 and 8 vice versa leading to processing of proKLK 7 thereby triggering its activation. Biol Chem 391:455-460

Oleksy A, Golonka E, Bańbuła A, Szmyd G, Moon J, Kubica M, Greenbaum D, Bogyo M, Foster TJ, Travis J, Potempa J (2004) Growth phase-dependent production of a cell wall-associated elastinolytic cysteine proteinase by Staphylococcus epidermidis. Biol Chem 385:525-535

Ono T, Ohara-Nemoto Y, Shimoyama Y, Okawara H, Kobayakawa T, Baba TT, Kimura S, Nemoto TK (2010) Amino acid residues modulating the activities of staphylococcal glutamylendopeptidases. Biol Chem 391:1221-1232

Oshida T, Sugai M, Komatsuzawa H, Hong YM, Suginaka H, Tomasz A (1995) A Staphylococcus aureus autolysin that has an Nacetylmuramoyl-L-alanine amidase domain and an endo-beta-Nacetylglucosaminidase domain: cloning, sequence analysis, and characterization. Proc Natl Acad Sci USA 92:285-289

O'Toole G, Kaplan HB, Kolter R (2000) Biofilm formation as microbial development. Annu Rev Microbiol 54:49-79

Patti JM, Allen BL, McGavin MJ, Höök M (1994) MSCRAMMmediated adherence of microorganisms to host tissues. Annu Rev Microbiol 48:585-617

Potempa J, Pike RN (2009) Corruption of innate immunity by bacterial proteases. J Innate Immun 1:70-87

Potempa J, Dubin A, Korzus G, Travis J (1988) Degradation of elastin by a cysteine proteinase from Staphylococcus aureus. J Biol Chem 263:2664-2667

Pragman AA, Schlievert PM (2004) Virulence regulation in Staphylococcus aureus: the need for in vivo analysis of virulence factor regulation. FEMS Immunol Med Microbiol 42:147-154

Rudack C, Sachse F, Albert N, Becker K, Eiff C von (2009) Immunomodulation of nasal epithelial cells by Staphylococcus aureusderived serine proteases. J Immunol 183:7592-7601

Schauber J, Gallo RL (2009) Antimicrobial peptides and the skin immune defense system. J Allergy Clin Immunol 124:R13-R18

Schmidtchen A, Frick IM, Andersson E, Tapper H, Björck L (2002) Proteinases of common pathogenic bacteria degrade and inactivate the antibacterial peptide LL-37. Mol Microbiol 46:157-168

Schmidtchen A, Holst E, Tapper H, Björck L (2003) Elastaseproducing Pseudomonas aeruginosa degrade plasma proteins and extracellular products of human skin and fibroblasts, and inhibit fibroblast growth. Microb Pathog 34:47-55

Schremmer-Danninger E, Hermann A, Fink E, Fritz H, Roscher AA (1999) Identification and occurrence of mRNAs for components of the kallikrein-kinin system in human skin and in skin diseases. Immunopharmacology 43:287-291

Sheehan BJ, Foster TJ, Dorman CJ, Park S, Stewart GS (1992) Osmotic and growth-phase dependent regulation of the eta gene of Staphylococcus aureus: a role for DNA supercoiling. Mol Gen Genet 232:49-57

Sieprawska-Lupa M, Mydel P, Krawczyk K, Wójcik K, Puklo M, Lupa B, Suder P, Silberring J, Reed M, Pohl J, Shafer W, McAleese F, Foster T, Travis J, Potempa J (2004) Degradation of human antimicrobial peptide LL-37 by Staphylococcus aureus-derived proteinases. Antimicrob Agents Chemother 48:4673-4679

Sjölinder H, Lövkvist L, Plant L, Eriksson J, Aro H, Jones A, Jonsson AB (2008) The ScpC protease of Streptococcus pyogenes affects the outcome of sepsis in a murine model. Infect Immun 76:3959-3966

Skrzeczyńska-Moncznik J, Wawro K, Stefańska A, Oleszycka E, Kulig P, Zabel BA, Sułkowski M, Kapińska-Mrowiecka M, CzubakMacugowska M, Butcher EC, Cichy J (2009) Potential role of chemerin in recruitment of plasmacytoid dendritic cells to diseased skin. Biochem Biophys Res Commun 380:323-327

Smagur J, Guzik K, Magiera L, Bzowska M, Gruca M, Thøgersen IB, Enghild JJ, Potempa J (2009a) A new pathway of staphylococcal pathogenesis: apoptosis-like death induced by staphopain B in human neutrophils and monocytes. J Innate Immun 1:98-108

Smagur J, Guzik K, Bzowska M, Kuzak M, Zarebski M, Kantyka T, Walski M, Gajkowska B, Potempa J (2009b) Staphylococcal cysteine protease staphopain B (SspB) induces rapid engulfment of human neutrophils and monocytes by macrophages. Biol Chem 390:361-371 
Sotiropoulou G, Pampalakis G (2010) Kallikrein-related peptidases: bridges between immune functions and extracellular matrix degradation. Biol Chem 391:321-331

Su YF, Chuang WJ, Wang SM, Chen WY, Chiang-Ni C, Lin YS, Wu JJ, Liu CC (2011) The deficient cleavage of M protein-bound IgG by IdeS: insight into the escape of Streptococcus pyogenes from antibody-mediated immunity. Mol Immunol 49:134-142

Suciu D, Inouye M (1996) The 19-residue pro-peptide of staphylococcal nuclease has a profound secretion-enhancing ability in Escherichia coli. Mol Microbiol 21:181-195

Sumitomo T, Nakata M, Higashino M, Jin Y, Terao Y, Fujinaga Y, Kawabata S (2011) Streptolysin S contributes to group A streptococcal translocation across an epithelial barrier. J Biol Chem 286:2750-2761

Terao Y, Mori Y, Yamaguchi M, Shimizu Y, Ooe K, Hamada S, Kawabata S (2008) Group A streptococcal cysteine protease degrades $\mathrm{C} 3(\mathrm{C} 3 \mathrm{~b})$ and contributes to evasion of innate immunity. J Biol Chem 283:6253-6260

Thulin P, Johansson L, Low DE, Gan BS, Kotb M, McGeer A, NorrbyTeglund A (2006) Viable group A streptococci in macrophages during acute soft tissue infection. PLoS Med 3:e53

Tobin AM, Lynch L, Kirby B, O'Farrelly C (2011) Natural killer cells in psoriasis. J Innate Immun 3:403-410

Trotonda MP, Manna AC, Cheung AL, Lasa I, Penades JR (2005) SarA positively controls bap-dependent biofilm formation in Staphylococcus aureus. J Bacteriol 187:5790-5798
Tsao N, Tsai WH, Lin YS, Chuang WJ, Wang CH, Kuo CF (2006) Streptococcal pyrogenic exotoxin B cleaves properdin and inhibits complement-mediated opsonophagocytosis. Biochem Biophys Res Commun 339:779-784

Wehner R, Dietze K, Bachmann M, Schmitz M (2011) The bidirectional crosstalk between human dendritic cells and natural killer cells. J Innate Immun 3:258-263

Wexler DE, Chenoweth DE, Cleary PP (1985) Mechanism of action of the group A streptococcal C5a inactivator. Proc Natl Acad Sci USA 82:8144-8148

Vincents B, Onnerfjord P, Gruca M, Potempa J, Abrahamson M (2007) Down-regulation of human extracellular cysteine protease inhibitors by the secreted staphylococcal cysteine proteases, staphopain A and B. Biol Chem 388:437-446

Vincents B, Vindebro R, Abrahamson M, Pawel-Rammingen U von (2008) The human protease inhibitor cystatin $\mathrm{C}$ is an activating cofactor for the streptococcal cysteine protease IdeS. Chem Biol 15:960-968

Wittamer V, Franssen JD, Vulcano M, Mirjolet JF, Le Poul E, Migeotte I, Brézillon S, Tyldesley R, Blanpain C, Detheux M, Mantovani A, Sozzani S, Vassart G, Parmentier M, Communi D (2003) Specific recruitment of antigen-presenting cells by chemerin, a novel processed ligand from human inflammatory fluids. J Exp Med 198:977-985

Yoshida S (2010) Klk8, a multifunctional protease in the brain and skin: analysis of knockout mice. Biol Chem 391:375-380 